\title{
Chronic use of opioids for nonmalignant pain: A prospective study
}

\author{
Perry N Fuchs PhD, Ann Gamsa PhD
}

\section{PN Fuchs, A Gamsa.}

Chronic use of opioids for nonmalignant pain: A prospective study.

Pain Res Manage 1997;2(2):101-107.

OBJECTIVE: To assess the effects of long term opioid therapy on pain, mood, and social and leisure activities in patients with chronic nonmalignant pain.

METHODS: Fourteen patients (eight males and six females) were treated with opioid medications for chronic nonmalignant pain not improved by previous treatments. Baseline measures of pain intensity were obtained before introducing opioids. Patients were monitored throughout the study, with outcome measured four to 32 months after opioids were started. The final measures examined drug dose, side effects, pain level, pain relief, emotional status, and involvement in social and leisure activities.

RESULTS: A total of $64.3 \%$ of patients reported good to excellent pain relief with opioid medication, and $64.3 \%$ reported reduced pain intensity, the decrease ranging from $25 \%$ to $100 \%$ (from baseline measures) on a scale rated from 0 to 10 . As well, $64.3 \%$ scored their emotional state as 5 or better on the 0 to 10 scale $(0$ indicating greatest distress), and $64.3 \%$ reported at least moderate (at least 5 on the 0 to 10 scale) involvement in leisure and social activities. There was a significant negative correlation between pain intensity and amount of leisure and social activity; $88.9 \%$ of patients who reported moderate to full involvement in leisure and social activities also noted decreased pain on the 0 to 10 scale. Other than one patient who developed tolerance, there were no notable problems with dose escalation or with any other form of substance abuse.

CONCLUSIONS: Some patients with chronic nonmalignant pain benefit from long term opioid therapy without developing unmanageable side effects, tolerance or substance abuse problems. These results, together with previous findings, show that opioids can be a safe and useful long term treatment for chronic nonmalignant pain.

Key Words: Chronic pain, Narcotics, Opioids

\section{Utilisation chronique d'opioïdes pour la douleur non cancéreuse : une étude prospective}

OBJECTIF : Étudier les effets d'un traitement de longue durée avec des opioïdes sur la douleur, l'humeur, les loisirs et les activités sociales chez les patients souffrant d'une douleur chronique non cancéreuse.

MÉTHODES : Quatorze patients (8 hommes et six femmes) ont été traités avec des médicaments contenant des opioïdes pour une douleur chronique non cancéreuse résistante aux autres formes de traitement. On a obtenu des valeurs de base de l'intensité de la douleur avant d'introduire les opioïdes. Les patients ont été monitorés pendant toute la durée de l'étude. On a mesuré les résultats de 4 à 32 mois après le début du traitement avec des opioïdes. L'étude des résultats finals portait sur la dose de médicament, les effets secondaires, le niveau de la douleur, le soulagement de la douleur, l'état émotionnel et la participation à des loisirs ou à des activités sociales. RÉSULTATS : Un total de $64,3 \%$ des patients ont qualifié le soulagement de la douleur de bon à excellent avec la médication opioïde, et $64,3 \%$ ont noté une diminution de l'intensité de la douleur, qui variait de $25 \%$ à $100 \%$ (par rapport aux valeurs de base) sur une échelle graduée de 0 à 10 . De même, $64,3 \%$ ont attribué une valeur de 5 et plus à leur état émotionnel sur une échelle de 0 à 10 (le zéro indiquant une souffrance émotionnelle maximale), et 64,3\% ont rapporté au moins une participation modérée (au moins 5 sur une échelle de 0 à 10) à des loisirs ou à des activités sociales. On a noté une corrélation négative significative entre l'intensité de la douleur et le degré de participation à des loisirs ou à des activités sociales ; 88,9\% des patients qui ont rapporté une participation modérée ou entière à des activités sociales ou de loisirs ont aussi noté une diminution de la douleur sur une échelle de 0 à 10 . Outre un patient qui a développé une accoutumance, on a relevé aucun problème lié à l'augmentation de doses ou à d'autres formes d'abus du médicament.

CONCLUSIONS : Certains patients qui souffrent d'une douleur chronique non cancéreuse peuvent bénéficier d'une thérapie de longue durée avec des opioïdes sans développer des effets secondaires incontrôlables, des problèmes d'accoutumance ou d'abus de substances. Les présents résultats ajoutés aux résultats antérieurs démontrent que les opioïdes sont sûrs et utiles dans un traitement de longue durée de la douleur chronique non cancéreuse.

McGill-Montreal General Hospital Pain Centre; Department of Psychology, McGill University, Montreal, Quebec

Correspondence and reprints: Dr A Gamsa, McGill-Montreal General Hospital Pain Centre, 1650 Cedar, Room L9 307, Montreal, Quebec

H3C 1A4. Telephone 514-934-8222, fax 514-934-8096

Received for publication September 16, 1996. Accepted January 16, 1997 
Io nadequately treated acute and chronic pain remains a major cause of suffering despite advances in knowledge in the field of pain. Chronic pain is especially difficult to manage because the physiological and psychological factors involved are often inextricable from each other; in general, people with pain represent one of the most challenging patient populations to treat. Reduction in discomfort and improved quality of life are the main goals of both pharmacological and nonpharmacological treatments for pain. What constitutes 'quality of life' differs from one person to another, but it is reasonable to assume that for most, increased function and improved emotional state are important. Brena and Sanders (1) have proposed that improved quality of life is signalled by an increase in general level of activity, reduction in environmental stress and, in some situations, a return to work.

To address the complex problems of chronic pain, specialized multidisciplinary pain treatment centres have been established in which specialists from various disciplines (anesthetists, family physicians, surgeons, psychiatrists, psychologists and physiotherapists) work together to formulate a course of action. Within this multidisciplinary approach, pharmacological therapy using various types of medications remains a common treatment modality. By far the most controversial agents used for the treatment of chronic nonmalignant pain are opioids, a group of drugs with pharmacological properties similar to opium or morphine. These medications have been generally accepted for the management of acute pain and pain caused by cancer (2).

For a number of reasons opioids are underused to treat persistent nonmalignant pain. First, there is lack of consensus concerning the efficacy of long term opioid therapy for chronic nonmalignant pain. Although the majority of studies report positive treatment outcome (3-9), some reports suggest that opioids are not effective and may, in fact, contribute to patients' problems $(8,10-13)$. Such negative findings have led to strong, sometimes irrational, statements against the use of opioids for chronic pain $(1,14)$, as shown in the following example: "The role of opioids in treating spinal pathology must be limited to the relief of acute symptoms because its chronic use does not address the pathological cause of the pain" (14, page 432). Such an assertion suggests that suffering be ignored if a treatable cause cannot be identified.

Second, the unfounded belief that patients will become addicted is another reason why opioids are underused. Doctors often fail to make the important distinction between physiological dependence and addiction. The term addiction refers to a pattern of behaviours marked by craving for the drug and by efforts to secure its supply in ever-increasing doses despite physical, psychological or social harm. Addiction involves psychological dependence. Physiological dependence, on the other hand, refers to the development of an abstinence syndrome on abrupt discontinuation of the drug (6). This is a physiological response related to the drug's properties. While physiological dependence is likely to occur with chronic opioid treatment and a certain degree of tolerance is to be expected over time, the risk of addiction as defined is remote $(6,15,16)$. Misconceptions concerning opioid medications have generated an 'opiophobia' (17), resulting in avoidance of their use in patients who might benefit.

The present study reports on an open trial of opioid medications for the treatment of chronic nonmalignant pain at the McGill-
Montreal General Hospital Pain Centre. It supports and extends results of previous studies that showed that long term opioid therapy can be a safe and useful option for treating chronic pain.

\section{PATIENTS AND METHODS}

The 14 subjects in this study were selected from patients referred to the McGill-Montreal General Hospital Pain Centre for treatment of chronic pain of various etiologies. Initially 17 patients were admitted into the study, but three who discontinued opioid therapy were later excluded. Patients who met the following inclusion criteria were selected: they were not on opioid therapy at the time of initial assessment; they had tried several nonopioid treatments without benefit; their participation in a trial of opioid medications was deemed clinically appropriate (based on medical and psychological assessment); they were on opioid therapy for a minimum of four months and were still taking opioid medication when the study was completed; they were able (with or without help) to complete the initial assessment questionnaire; and they were available to provide follow-up data.

The initial assessment questionnaire supplied the following information: pain intensity, demographic data, duration of pain, prior operations related to pain, prior opioid use, and type and dose of pain-relevant medications. As seen in Table 1 , there were six females and eight males, age range 28 to 75 years (mean 53). Site and type of pain varied, and included pain in the low back $(n=6)$, phantom limb $(n=4)$, upper thorax $(n=1)$, arm $(n=1)$, face $(n=1)$ and leg $(n=1)$. Duration of pain ranged from 2.5 to 32 years (mean 11.5), and number of pain-related operations ranged from none to 6 (mean 2.6). Two patients had no experience with opioids before the study while 12 previously had some short term opioid treatment. Nine patients were taking an antidepressant medication at the time of initial assessment. No patient was taking opioid medications for pain on a regular basis.

\section{Clinical procedures for all patients}

Initial assessment for all patients seen at the McGill-Montreal General Hospital Pain Centre consists of a comprehensive questionnaire and interviews with a medical doctor and a psychologist specializing in pain. After discussion by team members, a plan, typically comprising several treatment modalities, is implemented. This plan is tailored to the individual requirements of the patient and is drawn from a variety of treatment options, including drug regimen (antidepressants, adjuvant analgesics and adjustment of current medications), physiotherapy, trigger point injections, regional nerve blocks, counselling, group psychotherapy, physiotherapy, transcutaneous electrical nerve stimulation, acupuncture and hypnotherapy. Patients whose problems are particularly complex or unresponsive to initial treatments meet with the multidisciplinary team. If a reasonable attempt at pain management fails, opioid medications may then be considered. Other treatments are often continued concurrently with opioid therapy. If they met all inclusion criteria, patients were entered into the study when the opioid medication was introduced.

\section{Measures}

Outcome measures were obtained through a follow-up questionnaire administered in person or by telephone, four to 32 months (average duration 12.9 months) after the start of opioid therapy. The 
Opioid analgesia

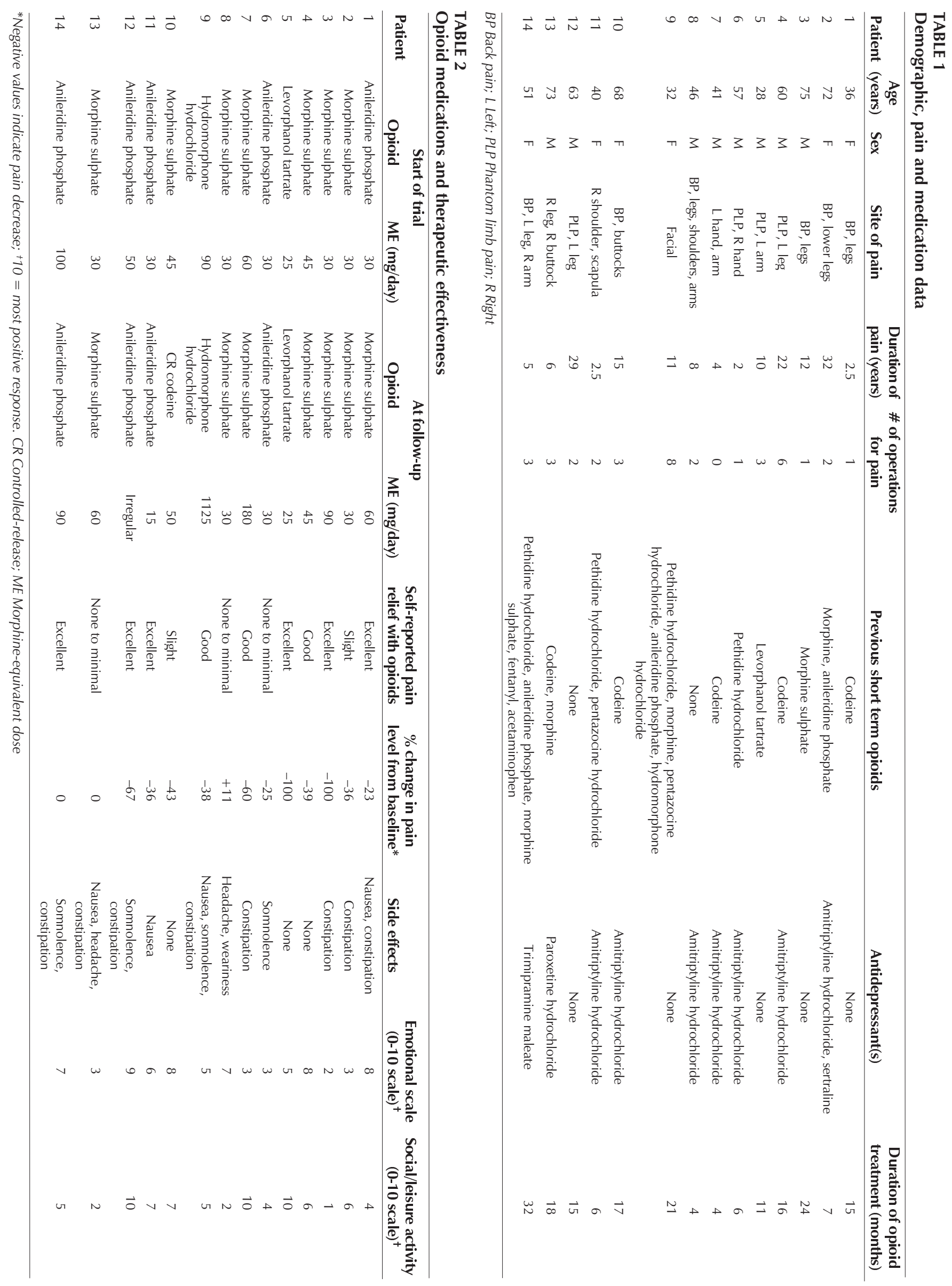




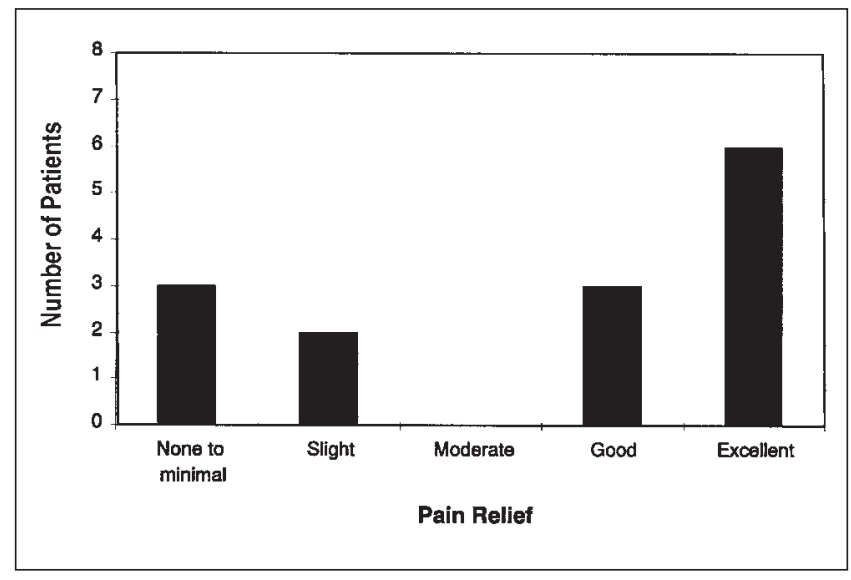

Figure 1) Self-reported pain relief with opioid medication

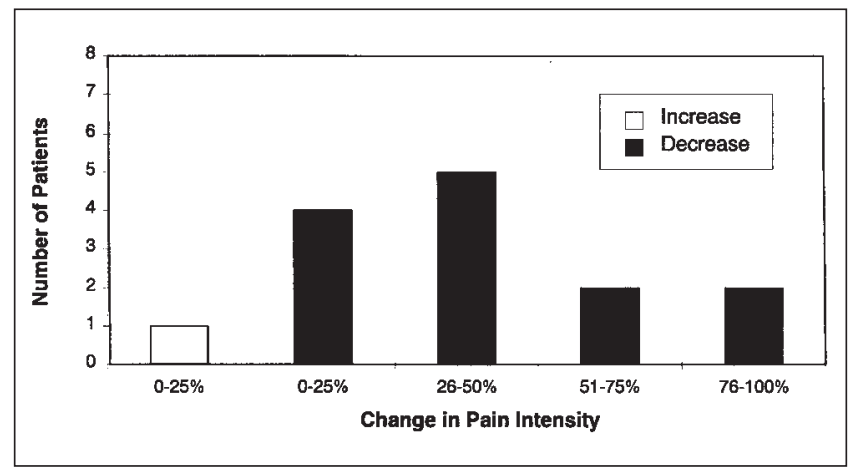

Figure 2) Change in pain intensity from baseline as measured by visual analogue scale

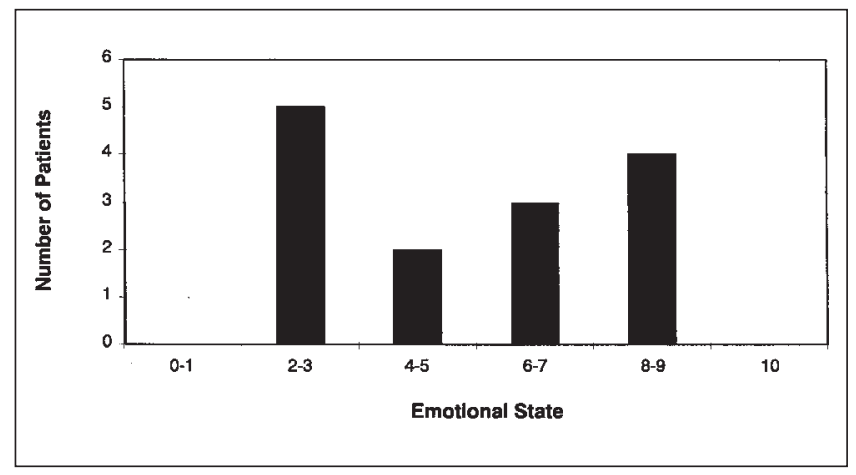

Figure 3) Self-reported emotional state on a scale from 0 to 10 where 0 represents the statement "I feel extremely distressed" and 10 represents the statement "I feel generally happy with life"

follow-up questionnaire assessed amount of pain relief with opioid medications; pain intensity; changes in opioid doses; side effects; emotional state; and involvement in social and leisure activities. Amount of pain relief with opioids was assessed by means of a five-point categorical scale (excellent: $81 \%$ to $100 \%$; good: $61 \%$ to $80 \%$; moderate: $41 \%$ to $60 \%$; slight: $21 \%$ to $40 \%$; minimal to none: $0 \%$ to $20 \%$ ). Patients also rated their current pain intensity on a scale ranked from 0 (no pain most of the time) to 10 (worst pain I can imagine most of the time). Information on current emotional state

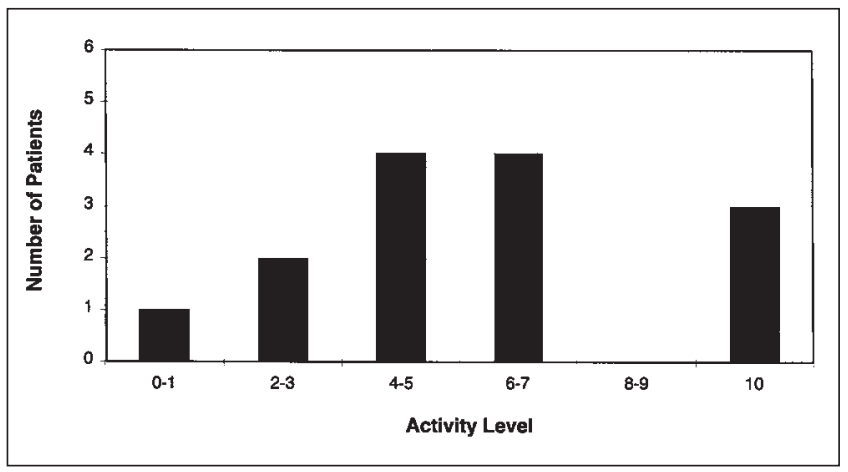

Figure 4) Self-reported social or leisure activity involvement on a scale from 0 to 10 where 0 represents the statement "I have had no involvement" and 10 represents the statement "I have been involved as much as ever"

and social/leisure activity was based on a 0 to 10 scale (emotional state: $0=$ I feel extremely distressed, $10=$ I feel generally happy with life; social and leisure activity: $0=\mathrm{I}$ have had no involvement, $10=\mathrm{I}$ have been involved as much as ever). Overall effectiveness of opioid therapy was assessed by examining amount of self-reported pain relief with opioids, percentage change of pain intensity from first questionnaire to follow-up, emotional state at follow-up and amount of social and leisure activity at follow-up.

\section{Pain relief and pain intensity}

Medications and therapeutic effectiveness at the time of longest follow-up are summarized in Table 2. As shown in Figure 1, 64.3\% of patients reported $60 \%$ or better pain relief with opioid medications. Six of these patients had excellent ( $81 \%$ to $100 \%)$ and three had good (61\% to $80 \%)$ relief from pain. As well, $64.3 \%$ of patients reported a notable decrease in pain intensity over baseline levels on the 0 to 10 scale $(26 \%$ to $50 \%$ decrease, $\mathrm{n}=5 ; 51 \%$ to $75 \%$ decrease, $\mathrm{n}=2 ; 76 \%$ to $100 \%$ decrease, $\mathrm{n}=2$ ), while $35.7 \%$ had very little change ( $0 \%$ to $25 \%$ decrease, $n=4$; increase in pain, $n=1)$ (Figure 2 ). Although the $26 \%$ to $50 \%$ decrease in pain intensity attained by five patients may not appear to be remarkable, it represents an improvement over other treatments, which failed to offer sustained relief. Two patients who reported excellent pain relief with opioids had less than $25 \%$ improvement in pain intensity.

\section{Emotional well-being and social/leisure activity}

When asked to select a number to best describe emotional state in recent weeks, $64.3 \%$ of patients selected 5 or better on a 0 to 10 scale (Figure 3). Figure 4 shows that on the same scale, $64.3 \%$ selected a score of 5 or greater to describe their amount of involvement in social and leisure activities.

The most desirable outcome would combine excellent pain relief with medication, decreased pain intensity over baseline levels, a high level of emotional well-being and active involvement in social and leisure activities. Closer examination revealed a significant inverse relationship between pain intensity on the 0 to 10 scale and amount of involvement in leisure and social activities, such that less pain accompanied more social and leisure activity $(\mathrm{r}=-0.55$, $\mathrm{P}<0.05$ ). Also, there was a trend towards an inverse relationship between pain intensity and pain relief with opioids $(\mathrm{r}=-0.45, \mathrm{P}<0.10)$. 
There was no significant relationship between the pain relief measure and either social and leisure activity or emotional well-being, nor between pain intensity and emotional well-being.

\section{Tolerance and side effects}

During the course of treatment, six patients had no change in opioid dose and three actually decreased their daily opioid intake. Of four who had modest dose increases, three reported good (61\% to $80 \%)$ or excellent ( $81 \%$ to $100 \%$ ) pain relief. The one patient (\#13) with dose increase and no reported benefit was on a modest dose of $60 \mathrm{mg} /$ day morphine sulphate. One patient (\#9) developed significant tolerance. Over 21 months, this patient's dose increased from 90 to $1125 \mathrm{mg}$ morphine-equivalent/day, with relief reported as good, and a decrease of $38 \%$ from the baseline level on the pain intensity scale. Side effects reported by patients in this study included nausea, constipation, itching, somnolence and headache. In general these effects were adequately managed and were not significant impediments to treatment. The three subjects who discontinued opioid use (and were dropped from the study) did so either because of side effects or because they received no benefit. They reported no difficulty withdrawing from the medication.

\section{DISCUSSION}

The aim of the present study was to examine the effectiveness of long term opioid therapy in relieving chronic nonmalignant pain of various etiologies. As well, side effects, development of tolerance to opioids, emotional state and involvement in social and leisure activities were studied. A majority of patients benefitted from opioid therapy as indicated by decreased pain intensity and reported relief from pain. All patients had pain unresponsive to other treatments for at least two years before regular opioid medications were started. Emotional state and involvement in social and leisure activities at follow-up were reported by the majority of patients to be 5 or better on a 0 to 10 scale. As well, decreased pain intensity was correlated with greater involvement in social and leisure activities.

It is difficult to make direct comparisons of opioid effectiveness across studies because different studies use different pain measures. Generally, it can be concluded that a majority of patients report some degree of pain relief, ranging from $29 \%$ to $100 \%(5,7,9$, $18,19)$. Follow-up lengths also vary (six months to seven years), but the majority of patients continue to report at least a $50 \%$ pain reduction with long term opioid therapy $(5,7,9,18,19)$.

In the present study, tolerance was not found to be a problem in the use of long term opioid therapy, except in the case of one patient. This patient suffered from severe unremitting facial pain, completely refractory to all treatments other than opioid medications, which provided pain relief rated as good. While dose and prescriptions were closely monitored and there was no abuse of the medication, the development of tolerance in this patient is of concern. During the course of treatment, with average duration of 12.9 months, six patients $(42.9 \%)$ had no change in their dose of medication and three (21.4\%) actually decreased their dose. Dose increased significantly in patient \#9 (described above). The remaining four patients (28.6\%), three of whom reported good to excellent pain relief and notable reductions in their pain scores, had modest dose increases. These results support findings of earlier studies that showed minimal risk of abuse behaviour and tolerance $(6,9)$. As well, the three patients who chose to discontinue opioid treatment during the course of the study reported no significant physical withdrawal symptoms, confirming earlier reports that opioids can be slowly tapered over several days and discontinued without problem $(6,9,20)$.

There was no evidence of abnormal drug-seeking behaviour in any patient in this study, which confirms previous reports. Tennant and colleagues (21) reported that $88 \%$ of 52 patients treated for more than 12 years reported adequate pain relief and that abuse behaviour was seen in only nine (17.3\%). Porter and Jick (15) assessed the occurrence of opioid addiction in 11,882 hospitalized patients who received opioids in the hospital. Only four $(0.03 \%)$ with no previous history of drug abuse showed abnormal drug-seeking behaviour indicative of addiction. Taub (22) found that only 13 of 313 patients with refractory pain who were maintained on opioid analgesics for up to six years posed serious management problems. All 13 patients in that study had previous histories of substance abuse. Taken together, these results clearly show that the potential benefit of opioid therapy to the well-being of selected patients with intractable pain outweighs the relatively small risk of abuse behaviour. Such risk is further reduced by guidelines used at the Montreal General Hospital Pain Centre, which include prescription by one physician, frequent small prescriptions and regular follow-up.

Importantly, sometimes a patient's attempt to obtain adequate analgesia is misconstrued as abnormal drug-seeking behaviour. While patients who express dissatisfaction when medication is not administered upon request in hospital or who require analgesics above amounts prescribed could be abusing medication, such behaviours more likely indicate inadequate dosing. In our pain centre, we generally start patients on very low doses of opioid medications and expect to titrate upwards. As well, in our view, a need for moderate dose escalation over time does not itself suggest 'addictive' tendencies, but rather expected and acceptable levels of tolerance. Exactly how much tolerance is acceptable over what time period needs to be clarified, but given the interindividual variability of response, rigid rules intended for all patients are unlikely to be useful.

Schug and Large (13) have proposed that optimal pain management would shift the chronic pain patient from an individual with pain and limited autonomy to one whose pain is minimal and whose autonomy is increased. In their view, there is no indication that opioid therapy reliably increases a patient's autonomy. In support of this position a number of reports $(8,11,12)$ suggest that opioid use correlates with greater physical and psychosocial impairment, a history of more operations and hospitalizations, and worse treatment outcome. To remedy these problems some behavioural treatment programs, such as the one described by Ralphs et al (23), aim to reduce and often eliminate the use of opioid medications. However, it is not evident that the patient's autonomy increases when analgesic medications are withdrawn or that suffering decreases.

Contrasting Schug and Large's contention, Tennant and Uelmen (24) found that almost $70 \%$ of patients maintained on opioids returned to employment and all were able to reduce medical visits and hospitalizations. Buttressing this, results of the present study showed that lower pain intensity was associated with greater involvement in social and leisure activities. If autonomy reflects a person's freedom to engage in activities of choice, then these results support the view that opioid medications can increase autonomy as well as decrease pain. 
Somerville (25) suggests that the notion of autonomy should include the patient's decision to make informed choices about medications. She contends that, if opioids are safe and not medically contraindicated, they should be offered to patients with full explanation of risks, benefits and alternate treatment options. In her view, to prohibit patients' access to opioids is to reduce their autonomy. In this regard one of our patients whose doctor had refused to prescribe opioids asked the second author, "Why do doctors think it's better for me to have pain than to be addicted?"

Our study failed to show a significant relationship between emotional well-being and either pain intensity or reports of pain relief with opioid medication. This seemingly counterintuitive finding is understandable when the numerous losses of patients who suffer from chronic pain are considered. In addition to job and financial losses, they suffer losses of dignity, physical attractiveness, sexuality, family, friends, confidence and self-esteem. These losses create emotional distress that is not quickly resolved when pain is relieved. Thus, it is strongly recommended that opioids be used in conjunction with a multidisciplinary approach that includes psychological intervention.

Schug and Large (13) argue that the general use of opioids would increase the likelihood of widespread inappropriate prescribing. We could not agree more that extreme caution is necessary in the long term prescription of opioids, and that careful medical and psychological assessment along with ongoing monitoring are required. At the McGill-Montreal General Hospital Pain Centre, patients are assessed by members of a multidisciplinary team that includes specialists in family medicine, neurosurgery, anesthesia, psychiatry, psychology and physiotherapy. A treatment plan, typically combining several treatment modalities, is then devised. Nonopioid treatments are usually tried first, and only if they fail to help are opioids introduced for selected patients. Selection is determined by the clinical appropriateness of the drug for a given patient, with pain as well as medical and psychological status considered. Patients with a history of substance abuse are very closely monitored when opioids are recommended. All patients are followed on a regular basis to ensure proper use of medications and to assess need for adjustment.

Of special interest is that four of the 14 patients in this study had phantom limb pain, a particularly difficult problem to treat. Two obtained excellent and one obtained good pain relief, confirming the results of Urban et al (19) who found that opioids can be safely and successfully used for long term management of phantom limb pain. While the present study did not address the question of relative efficacy of opioid therapy for different types of chronic pain, we can note that opioids were helpful for phantom limb pain. Others have suggested that non-nociceptive pain is relatively opioid-resistant (26). However, Pappagallo et al (5) and Rowbotham et al (27) found excellent relief of postherpetic neuralgia with opioids, and a review of the literature by Portenoy et al (28) showed that there are patients with neuropathic pain who respond to opioid drugs. Further study to determine the efficacy of opioids for different types of chronic pain is needed.

A second study to examine the effectiveness of long term opioid therapy in chronic nonmalignant pain is underway at our pain centre. In that study, changes have been made to the methodology to improve the weaknesses in the present report. Because the prime aim of the present study was to assess effectiveness of opioid medi- cations in relieving pain, baseline measures for emotional state and involvement in social and leisure activities were not obtained. In the second study, several indicators of function and emotional state are being measured at initial assessment and at follow-up. Follow-up data will be obtained after a three-month period of opioid therapy, and then again at nine to 12 months.

\section{CONCLUSIONS}

The accumulated research provides evidence that, in some patients long term opioid therapy is a useful treatment for chronic nonmalignant pain. Many patients whose pain has failed to respond to other treatments benefit from opioids without developing significant tolerance (although dosage may need to be increased until a therapeutic level is attained). While patients are likely to become 'dependent' on the medication - suffering an abstinence syndrome in the case of abrupt dose decrease or medication withdrawal - they are unlikely to become 'addicted' - craving the drug at escalating doses and pursuing it despite physical, psychological and social harm. Of course, there are exceptions, and if the medication is not helping or is being abused it should be discontinued.

In many ways the risks and benefits of using opioids in chronic nonmalignant pain are neither better nor worse than those of other medications. Like other medications, opioids have side effects, and in any given patient opioids may not help. Yet for some patients whose lives are made miserable by suffering, opioids may bring relief where other interventions have failed. In such cases it is neither rational nor humane to withhold a potentially effective treatment, as long as appropriate guidelines are followed and precautions taken. Rather than repeatedly pursue research concerning addiction and tolerance, future work must address important questions such as the population of patients most likely to benefit from opioid therapy. The reality is that for some patients opioids may be the only effective remedy for intractable nonmalignant pain.

ACKNOWLEDGEMENTS: This research was supported by NSERC grant 7891 to Dr Ronald Melzack and by the McGill-Montreal General Hospital Pain Centre fund. The authors thank Eva Bild for assistance in data collection and Dr Geoffrey Schultz for helpful comments on the manuscript.

\section{REFERENCES}

1. Brena SF, Sanders SH. Opioids in nonmalignant pain: Questions in search of answers. Clinical J Pain 1991;7:342-5.

2. Gourlay GK, Cousins MJ. Strong analgesics in severe pain. Drugs 1984;28:79-91.

3. Arkinstall W, Sandler A, Goughnour B, Babul N, Harsanyi Z, Darke AC. Efficacy of controlled-release codeine in chronic non-malignant pain: A randomized, placebo controlled clinical trial. Pain 1995;62:169-78.

4. Moulin DE, Lezzi A, Amireh R, Sharpe WKJ, Boyd D, Merskey H. Randomised trial of oral morphine for chronic non-cancer pain. Lancet 1996;347:143-7.

5. Pappagallo M, Raja SN, Haythornthwaite JA, Clark M, Campbell JN. Oral opioids in the management of postherpetic neuralgia: A prospective survey. Analgesia 1994;1:51-5.

6. Portenoy RK. Chronic opioid therapy in nonmalignant pain. J Pain Symptom Manage 1990;5:S46-62.

7. Portenoy RK, Foley KM. Chronic use of opioid analgesics in non-malignant pain: Report of 38 cases. Pain 1986;25:171-86.

8. Turner JA, Calsyn DA, Fordyce WE, Ready LB. Drug utilization patterns in chronic pain patients. Pain 1982;12:357-63.

9. Zenz M, Strumpf M, Tryba M. Long-term oral opioid therapy 
in patients with chronic nonmalignant pain. J Pain Symptom Manage 1992;7:69-77.

10. Arnér S, Meyerson BA. Lack of analgesic effect of opioids on neuropathic and idiopathic forms of pain. Pain 1988;33:11-23.

11. Maruta T, Swanson DW. Problems with the use of oxycodone compound in patients with chronic pain. Pain 1981;11:389-96.

12. Maruta T, Swanson DW, Finlayson RE. Drug abuse and dependency in patients with chronic pain. Mayo Clin Proc 1979;54:241-4.

13. Schug SA, Large RG. Opioids for chronic noncancer pain. Pain: Clinical Updates 1995;3:1-4.

14. Dillin W, Uppal GS. Analysis of medications used in the treatment of cervical disk degeneration. Orthoped Clin North Am 1992;23:421-33.

15. Porter J, Jick H. Addiction rate in patients treated with narcotics. N Engl J Med 1980;302:123.

16. Melzack R. The tragedy of needless pain. Sci Am 1990;2:27-33.

17. Morgan JP. American opiophobia: Customary underutilization of opioid analgesics. In: Hill CS, Fields WS, eds. Advances in Pain Research and Therapy, vol 11. New York: Raven Press, 1989:181-9.

18. France RD, Urba BJ, Keefe FJ. Long-term use of narcotic analgesics in chronic pain. Soc Sci Med 1984;19:1379-82.

19. Urban BJ, France RD, Steinberger EK, Scott DL, Maltbie AA. Longterm use of narcotic/antidepressant medication in the management of phantom limb pain. Pain 1986;24:191-6.
20. Evans PJD. Narcotic addiction in patients with chronic pain. Anaesthesia 1981;36:597-602.

21. Tennant FS, Robinson D, Sagherian A, Seecof R. Chronic opioid treatment of intractable non-malignant pain. Pain Manage 1988;Jan/Feb:18,26.

22. Taub A. Opioid analgesics in the treatment of chronic intractable pain of non-neoplastic origin. In: Kithata LM, Collins JG, eds. Narcotic Analgesics in Anesthesiology. Baltimore: Williams \& Wilkins, 1982:199-208.

23. Ralphs JA, Williams A, Richardson PH, Pither CE, Nicholas MK. Opiate reduction in chronic pain patients: A comparison of patient-controlled reduction and staff controlled cocktail methods. Pain 1994;56:279-88.

24. Tennant FS, Uelmen GF. Narcotic maintenance for chronic pain: Medical and legal guidelines. Postgrad Med 1983;73:81-94.

25. Somerville MA. Opioids for chronic pain of non-malignant origin coercion or consent? Health Care Analysis 1995;3:12-4.

26. Hansson P. Neurogenic pain: Diagnosis and treatment. Pain: Clinical Updates 1994;2:1-4.

27. Rowbotham MC, Reisner-Keller LA, Fields HL. Both intravenous lidocaine and morphine reduce the pain of postherpetic neuralgia. Neurology 1991;41:1024-8.

28. Portenoy RK, Foley KM, Inturrisi CE. The nature of opioid responsiveness and its implications for neuropathic pain: New hypotheses derived from studies of opioid infusions. Pain 1990;43:273-86 


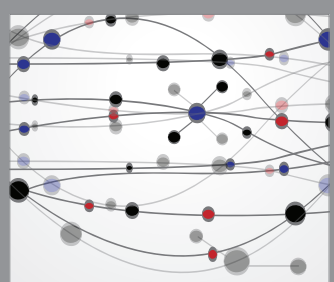

The Scientific World Journal
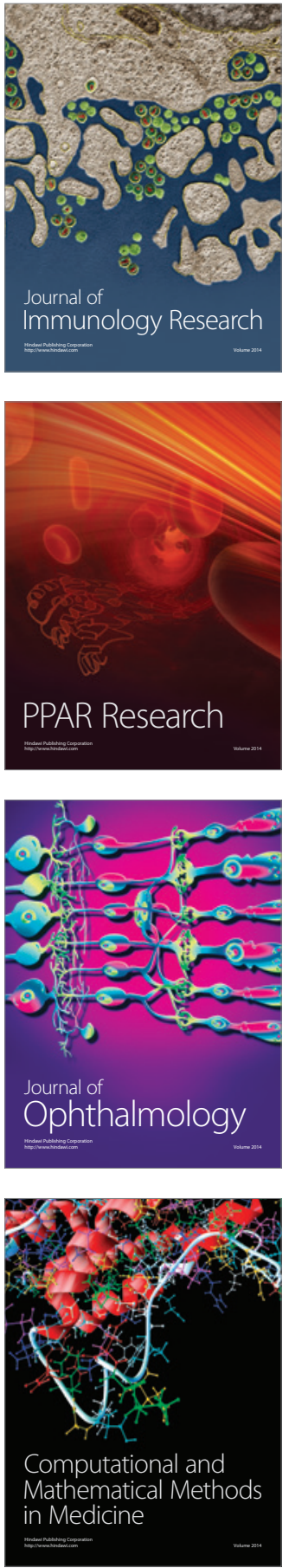

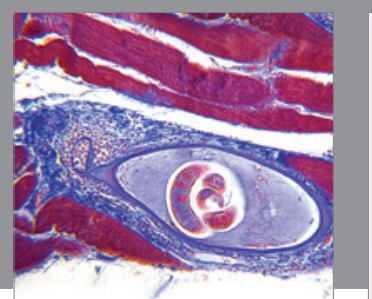

Gastroenterology Research and Practice

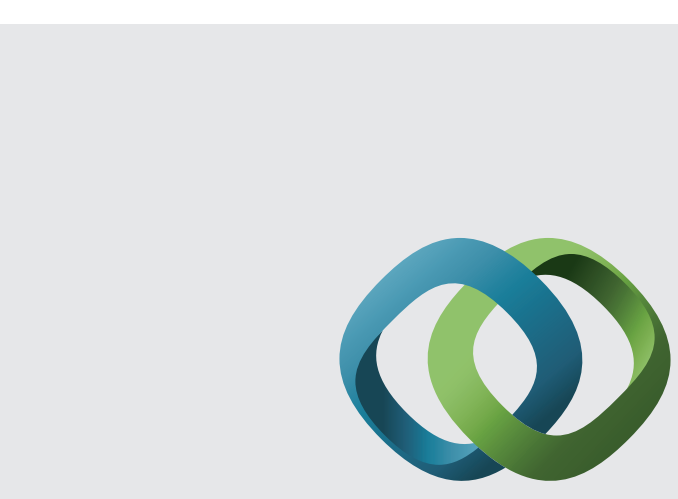

\section{Hindawi}

Submit your manuscripts at

http://www.hindawi.com
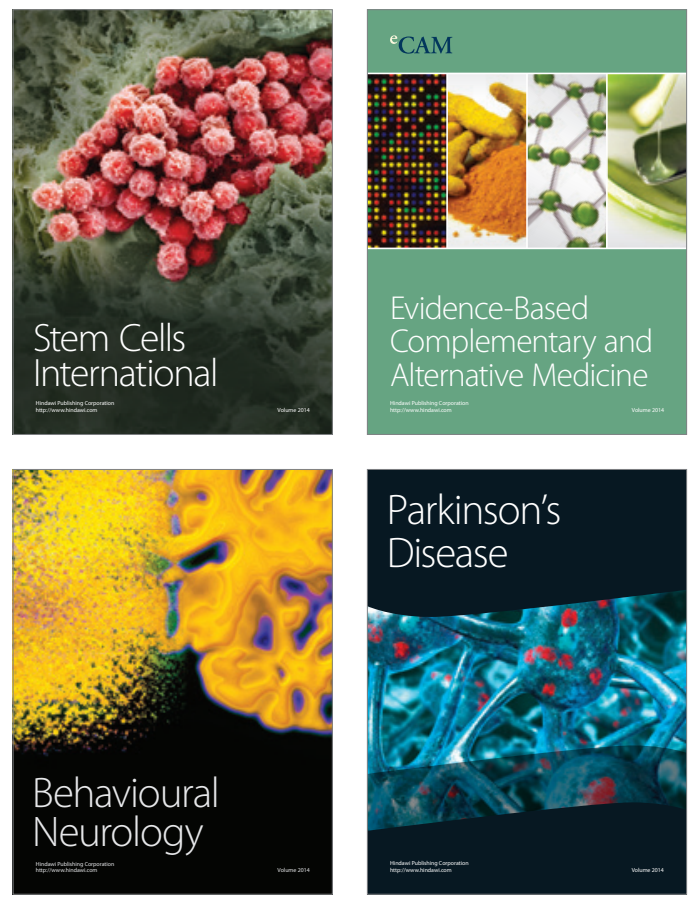
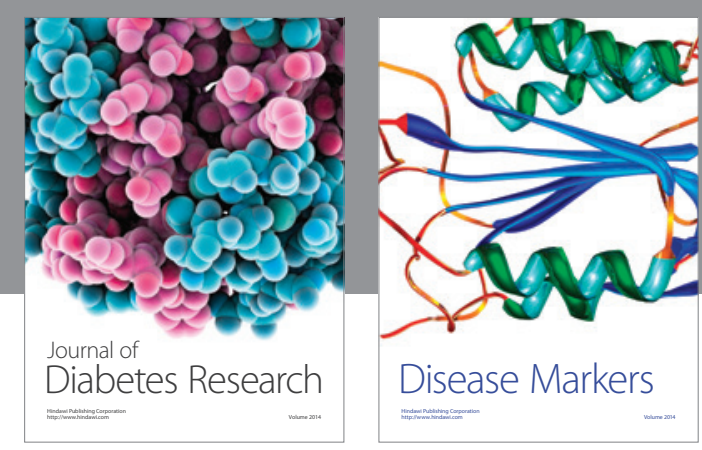

Disease Markers
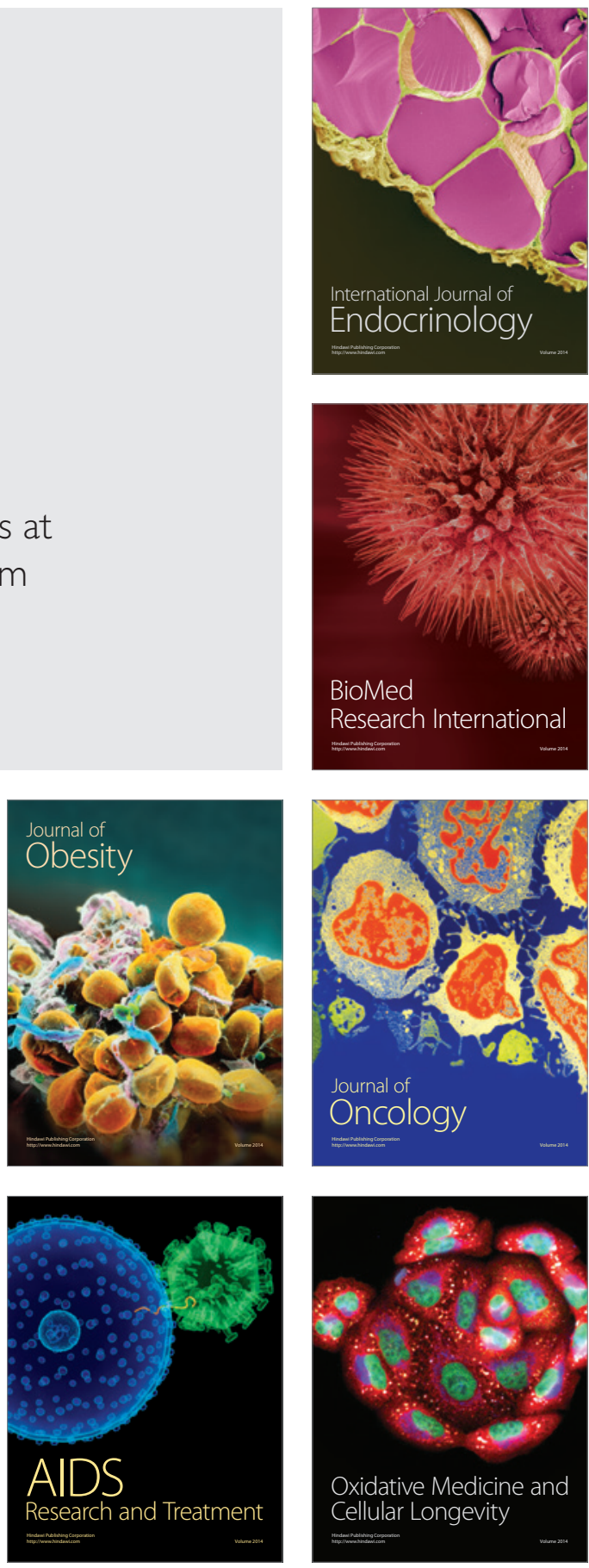